\title{
EFFECTIVE ACADEMIC ENGLISH COURSES IN TOURISM: AN INTERDISCIPLINARY APPROACH AS A TOOL FOR SUCCESS
}

\author{
Albena Stefanova ${ }^{1}$ \\ Georgi Zabunov²
}

DOI: https://doi.org/10.31410/tmt.2020.619

\begin{abstract}
The purpose of this chapter is to present an interdisciplinary approach to developing effective academic English courses in tourism. The authors propose to use the synergy of English for Specific Purposes (ESP) theory, Systemic-Structural Activity Theory (SSAT) and selected marketing techniques. Based on an analysis of the specialised literature, it is stated that the engagement of learners is a key factor for effective language learning. The possibilities for using adapted marketing techniques to increase engagement by increasing involvement are discussed in the chapter. The authors propose approaches for defining the target vocabulary and for increasing the motivation for learning based on the theory of ESP and SSAT.
\end{abstract}

Keywords: English for Specific Purposes (ESP), Student engagement, Systemic-Structural Activity Theory (SSAT), Consumer engagement.

\section{INTRODUCTION}

$\mathrm{I}^{\mathrm{n}}$ $\mathrm{n}$ the modern times of globalisation and internationalisation, the sector of tourism needs highly qualified employees more than ever in order to be competitive and provide effective management and operation. Communication within a business and with customers and partners worldwide is more intensive and challenging in terms of the Internet and social media. Workers of foreign origin, multinational companies, international contacts with a variety of nationalities and cultures - language education and the knowledge of two or three foreign languages are a must for all stakeholders involved in the sector. This requires the acquisition of new knowledge and skills related to the specific features of each new media which not only involves vocabulary, grammar, genre, register, etc., but certain interdisciplinary knowledge and skills related to business in areas such as advertising, marketing, customer care. It is, therefore, essential for educational institutions to offer adequate and modern courses in foreign languages for specific purposes that provide the required knowledge and skills and take into consideration the characteristics of the modern generations, generation $\mathrm{Z}$ and the millennials. When designing courses, it should also be borne in mind that the Internet and social media have changed everyday communication and have a specific discourse that must be acquired for effective business relations in addition to general business correspondence and communication. At the same time, it is possible to take advantage of the new means of communication to facilitate learning and enhance student performance. Thus, by achieving higher student engagement we can optimise course effectiveness and, hence, prepare more highly qualified specialists ready to add value to any business in the sector of tourism.

Having considered this issue from the perspective of academic experts in English and economics, we have come to the idea that it is possible to apply an interdisciplinary approach involving

University of National and World Economy, Student Town, 1700 Sofia, Bulgaria

University of National and World Economy, Student Town, 1700 Sofia, Bulgaria 
novelties in language teaching and the introduction of marketing techniques employed to increase consumer involvement in order to improve course parameters and, hence, course effectiveness. Concerning the need to determine the most appropriate topics and lexis to be taught, we have to define precisely the areas students will study. For this purpose, we suggest using the Systemic-Structural Activity Theory (SSAT) and the marketing theory of involvement.

\section{ENGLISH FOR SPECIFIC PURPOSES}

English for tourism is part of English for specific purposes, ESP. The reasons for the emergence of ESP are related to the socio-political development of mankind especially in the post-war world after 1945. These reasons include the needs of the society, the revolution in the area of linguistics and the shift in the learning focus to the learner. With the increasing internationalisation of human activities and later on with globalisation, the modern world needed more as well as specific courses in English that could meet the expectations and requirements of all sectors of the economy. This is how courses for accounting, agriculture, aviation, hospitality industry, oil industry, financing, banking, etc. were designed and offered. The revolution in linguistics which started in the second half of the last century led to a greater interest in learner's needs, motivation, personal characteristics and ways of learning. More attention was paid to communication and communicative competence with all its components. Scientists focused more on authentic communication environment, learning and teaching strategies, materials design and the differences between written and spoken English and between formal and informal register.

According to the definition of English for specific purposes suggested by Strevens (1988), it has absolute and variable characteristics. The absolute ones include meeting the specific needs of the learner; specific content related to professions and areas; a focus on the specific language needed for operation in a particular field in terms of grammatical structures, vocabulary, discourse, etc.; and it is always considered and taught in comparison with General English (GE) or English for general purposes. Because of their nature, the variable characteristics may include the limitation of ESP to a certain skill such as writing, for example, and involves the use of a predefined teaching methodology (Strevens, 1988, p. 7).

Ten years later, in 1998, Dudley-Evans and St. John offered a revision of this definition with three absolute and five variable characteristics. The absolute characteristics include the satisfaction of the specific needs of the learner, the employment of the methodology and activities of the subject ESP serves and the focus on the specific language appropriate for these specific activities. The variable characteristics include the possibility for ESP: to be related to given subjects; in specific learning situations, to resort to the methodology which is different from that of General English; generally oriented to adult learners from higher education institutions or particular fields; to be studied by intermediate or advanced learners; and taught to beginners if assumed that they have basic knowledge of the language system (Dudley-Evans and St John, 1998, pp. 4-5).

Defining ESP involves its types as well. In 1983, Carter suggested a classification of three main types of ESP, which was accepted by scholars. The first type is English as a restricted language, meaning that this type is restricted in its use within a certain profession like that of air traffic controllers. It is very specialised and its repertoire is restricted to specific situations. The second and most common one is English for academic and occupational purposes. As its name implies, it involves the studying of English for professional goals and comprises a multitude of areas such as English for medicine, English for law, English for engineering, etc. The third type 
is English with specific topics and involves the studying of particular topics related to a given situation (Carter, 1983).

The differences between ESP and GE (General English) mean that ESP courses differ as well as they aim at developing and mastering specific competences. Carter distinguished three key features of ESP courses: authentic materials, specific purpose and self-direction (Carter, 1983, p.134). Authentic materials are of paramount importance as they provide the specific context, lexis, grammar, discourse and facilitate the acquisition and improvement of specific learner competences and contribute to effective teaching and learning. Specific purpose provides the focus of the course because it can aim at developing all or some skills. For instance, a course can be aimed at effective presentations or at business writing. Self-direction means that the language learner is also a proficient user who has achieved a level of communicative competence that ensures the independence to decide how, what, when or where to learn in order to satisfy their language needs.

Another distinction related to ESP is its syllabus seen by Cummins (1979) as a dichotomy between the basic interpersonal communicative skills (BICS) and the cognitive academic language proficiency (CALP). BICS are related to informal communication with colleagues, relatives and friends, whereas CALP refers to the sophisticated usage of the language in an academic context. Researchers like Gatehouse (2001) think that using this dichotomy and in order to be competitive and successful in their career path, learners have to acquire three basic skills: the specific jargon of the particular profession; the acquisition of a set of more general academic skills; and the ability to use the language to communicate effectively and regardless of the occupational area and its context. Thus it is possible to conclude that an effective course in ESP needs a syllabus including these topics and activities and ensuring the optimised acquisition of specific language knowledge and skills.

Course effectiveness is related to the composition of a learner group. Learners can differ in age, language level, professional experience and background, individual needs, motivation and learning style. This means that with a heterogeneous group it is more challenging to work and achieve results compared to homogeneous groups and an ESP expert needs to allocate more time to prepare materials and to offer activities and tasks that can contribute to the effective learning process of the particular group.

An important facet of ESP that should be considered is materials selection since each ESP course has its own specific features such as learner characteristics, professional area, group composition, focus, etc. Therefore, no textbook can be sufficient alone for the achievement of course objectives, and materials are usually tailor-made. There is a correlation between their quality and appropriateness on one hand, and the ESP professional's expertise, experience and motivation, on the other.

A vital aspect of ESP is the language expert or ESP practitioner (Dudley-Evans and St John, 1998). Dudley-Evans and St John use the term to highlight the five roles of the ESP specialist which include: a teacher, a curriculum designer, a consultant, a researcher and an assessor. Each of them can be typical of a course stage with two or more involved at a time depending on the particular learning situation and context. It is, therefore, of key significance for an ESP practitioner to have specific knowledge related to the subject matter and professional context as well as strong motivation and considerable resourcefulness and creativity. 
Being part of English for specific purposes, English for tourism has all characteristic features of ESP and to provide an effective course in it, we need to give all these aspects careful consideration along with the requirements of academic institutions and a particular university.

\section{ACADEMIC COURSES IN ENGLISH FOR TOURISM: SPECIFICS}

With the development of aviation and the increased welfare of a large part of the world's population, the need for courses in English for tourism became pressing. A variety of courses has been offered from English for the hospitality industry to English for hoteliers and restaurateurs. Academic courses in English for specific purposes for students of tourism involve the development and improvement of communicative competence along with the acquisition of subject matter. They are aimed at preparing competitive professionals who can operate as managers, entrepreneurs, employees in travel agencies or for tour operators, event managers, etc. in the sector of tourism. Their course is designed to cover the key topics of the subject matter such as types of tourism, reservations, organising events, catering, types of accommodation, types of transportation, etc. with variation according to the particular sub-sector. At the same time, it is also intended to develop and improve specific student communicative competence in terms of knowledge and skills related to effective business communication such as writing proposals, requests, dealing with complaints, organising events and travels, preparing leaflets and brochures. Communicative competence and knowledge of subject matter can be achieved using the traditional courses in foreign languages for specific purposes. Focusing on English as the lingua franca of today's world, this implies the use of a textbook in tourism. Generally, textbooks cover the most common topics and activities in a classical way, i.e. a way associated with more strictly defined roles and formal classes. Learners can be involved in role plays, simulations and case studies or assigned the writing of reports, proposals or business letters as single tasks involving one or two skills (e.g. listening and speaking or reading and writing). Additional materials can be used as well as course packs in order to meet the particular needs of the stakeholders in a country or region, including students. The quality, variety and appropriateness of these materials depend on the ESP expert's background, experience, motivation and personal qualities such as resourcefulness and creativity. However, the tasks are usually focused on one or two skills and are not interactive in terms of involving more activities, the use of the Internet and social media nor a different student composition such as individual, pair, small-group or all-group participation within an assignment of one big task or several tasks. Another weakness of this classical way of education is the fact that students do not change their roles- they are not allowed to be teachers in terms of consulting, assessing, encouraging or designing materials. Generally, they are not given the possibility to choose the topics to study or the issues to discuss. Hence, motivation and learner engagement are not employed to the extent that would bring satisfaction and optimal ESP acquisition. Furthermore, the new generations' flair for digital interaction is hardly taken account of and used.

Having considered all these aspects, the authors have come up with the idea of using an interdisciplinary approach in order to ensure greater course effectiveness. By introducing novel, interactive tasks and using marketing techniques we enhance student engagement. Learners are seen as consumers buying a particular educational product and choosing a particular educational service. Increased student engagement leads to greater overall motivation and hence to improved performance and course effectiveness. 


\section{STUDENT ENGAGEMENT}

The success of any activity is determined by the motivation of the agent. It is a set of motives involving needs, ideals, personal goals, aspirations, interests. If there is no or low motivation, the activity will either not be conducted at all or its quality will be doubtful. Applied to learning, this means that learning will be unsuccessful, performance unsatisfactory and no proficiency will be achieved unless there is the motivation for learning. That is why De Bot, Lowie and Vespoor conclude that highly motivated learners have higher chances to learn better (De Bot, Lowie, \& Vespoor, 2005). Motivation is influenced by two types of factors: extrinsic, related to the performance of activities followed by a kind of praise or reward, and intrinsic, related to the satisfaction of personal needs with the activities themselves seen as a reward. Extrinsic factors or extrinsic motivation are associated with a higher position at work, a better salary, i.e. with the expectation of a promotion or a benefit. With intrinsic motivation, the individual's desire for personal improvement and satisfaction and therefore for contribution to the welfare of a society or organisation leads to enhanced performance. Intrinsic motivation is considered engagement. In terms of learning, Bender suggests the following definition of engagement: "engagement may be defined as cognitive investment in, active participation with, and emotional commitment to learning particular content" (Bender, 2017, p.2). Martin and Torres define engagement as "meaningful student involvement throughout the learning environment" (Martin and Torres, 2016, p.1). Thus they see it as a relationship between the student and the learning environment which includes the learning community, the teachers, the curriculum, the teaching methodology, the peers (Martin and Torres, 2016, p.1). Therefore, this construct comprises of three types of engagement: cognitive- related to students' investment in learning, behavioural- related to student participation in learning related activities; and emotional- related to the reactions to teachers, educational institution, peers. Fredricks et al. conclude that "student engagement is increasingly viewed as one of the keys to addressing problems such as low achievement, boredom and alienation, and high dropout rates" (Fredricks et al., 2004, p.59). Engaged students are motivated students who are more likely to perform better and achieve better results. Engagement, however, can vary in time and duration. Thus, if we manage to ensure increased student engagement over a longer period, ideally throughout the whole course, we will achieve greater course effectiveness and better student performance.

When examining student engagement, we find it essential to take into account that the characteristic features of modern generations for different generations have different needs and interests and should, therefore, be approached accordingly in order to achieve success in teaching them. The learning context differs as well. As mentioned above, contemporary world is driven by information and communication technologies. The new generations, generation $\mathrm{Z}$ and the Millennials, which are also called digital natives, have a natural flair for this kind of technology. They show greater engagement if their education involves it and is more interactive and dynamic. This suggests that course effectiveness and teaching approaches should be adapted to these new challenges. In foreign language education for specific purposes this means that novel techniques should be introduced and different authentic materials should be used in order to provide more interactive tasks and involve students as co-creators of learning content. Windham (2005) suggests that to achieve increased student engagement new courses must include interaction, exploration, relevancy, multimedia and instruction. Following these trends in learning and taking into consideration the fact that apart from being learners, students can be seen as consumers of an educational product; we have come to the idea of applying the abovementioned interdisciplinary approach combining conventional English language teaching approaches with 
marketing techniques. Thus, higher engagement can be achieved based on samples, promotions and first-hand experience, and greater involvement in the learning process allowing learners to consult, partner and cooperate with the teacher towards the achievement of language and subject matter acquisition and, ultimately, towards their more effective preparation for effective functioning at a professional level after graduation.

\section{SYSTEMIC-STRUCTURAL ACTIVITY THEORY AND ENGLISH FOR TOURISM}

As mentioned, modern tourism is a complex activity and its study requires the application of an interdisciplinary approach. In itself, the interdisciplinary approach is an interesting phenomenon and deserves special attention. The desire to study socio-economic phenomena in all their complexity and diversity contributed to the emergence of different research approaches to the mid-1970s. Interdisciplinary approaches enrich the classical disciplinary ones by focusing not on the acquisition of classical disciplinary knowledge, but on the synthesis of new knowledge about the studied objects by searching for similar subject areas in them. This allows the use of the methodology of one discipline to solve the problems of another discipline. At the same time, the language of these disciplines is mutually enriched, as well as their disciplinary methodology is improved. Therefore, the successful application of the multidisciplinary approach requires the joint work of professionals from different fields who study a common subject. From a practical point of view, it is not an easy task to form a team of professionals from different fields to solve specific practical problems. The task becomes even more complicated when a team of scientific researchers has to be formed for the needs of the practice. In this case, the correct scientific approach is to apply a multidisciplinary research scheme that combines the views of scientists from different theoretical fields. For this reason, we propose to use the Systemic-Structural Activity Theory (SSAT) to determine the learning tasks in studying English for tourism.

In its essence, the Systemic-Structural Activity Theory (SSAT) is a synthesis of contemporary work activity studies. These studies are interdisciplinary and are most often carried out within the framework of ergonomics, management, psychology and economics. Although SSAT is a psychological theory, it was developed in a way that provides for work activity studies from the perspective of various scientific disciplines. SSAT emerged as a development of the ideas of the General Activity Theory (GAT) and the Applied Activity Theory (AAT). Since the theoretical constructs of the GAT are at a high level of theoretical abstraction, it is not appropriate for the study of human work activities. New avenues for applied research should be sought. This is how AAT and later SSAT emerged. Currently, SSAT is a separate and independent approach to work activity analysis and differs significantly from all other approaches. According to SSAT, activity is systematic and goal-driven. Goals are achieved consciously by a mechanism of self-regulation. A process unfolds in which cognition, behaviour, and motivation are integrated and organised. Being familiar with this process details, scholars can study the motivation for task performance in a work activity as well as the impact of environmental factors on this motivation. The purpose of the considered process is to precisely define the work tasks and to motivate the people who will perform them. Therefore, SSAT can be used to identify areas of study and to increase student motivation.

SSAT emerged as a natural and logical development of the General Activity Theory (GAT) ideas. In its essence, AT is an umbrella term for a broad variety of psychological, social- psychological, socio-cultural and other theories and studies. They all originate from the Activity Theory 
that was formulated in the Soviet Union. Its founders are Lev Vygotsky, Alexei Leontiev and Sergei Rubinstein (Yasnitsky, 2018). The main idea of this theory is that human activity is a systematic and socially determined phenomenon.

The Western psychological thought discovers AT after a group of Scandinavian scientists turned their attention to it (Engeström, 1987). Scandinavian scholars' research allowed to amalgamate the major ideas of AT with the achievements of Western psychological science.

These are the prerequisites for the emergence of the Applied Activity Theory (AAT). It applies research methods of cognitive psychology within the theoretical framework of the General Activity Theory. An overview of the achievements of this theory was first systemized in the Theoretical Issues in Ergonomics Science (TIES) (Bedny, 2004).

The founders of SSAT are Gregory Z. Bedny, Inna Bedny, and Waldemar Karwowski. Being a further development of the ideas and concepts of the GAT and the AAT, SSAT focuses on the concept of activity. SSAT is intended for practical application which affects the interpretation of the concept. The theory founders state: "We understand activity as a self-regulated system that integrates cognitive, behavioural, and emotional-motivational components, and is directed toward achieving a conscious goal of activity" (Bedny, Bedny, and Karwowski, 2019, p. 5). SSAT is a common theoretical framework for management studies and work psychology. The theory terminology is well-developed and includes basic concepts that are suitable for practical application. The main theoretical scheme allows the use of both qualitative and quantitative scientific methods of research. Activity has a purposeful nature and systematically covers the external behaviour as well as the internal mental and emotional-motivational processes (Bedny, Karwowski, 2011). An important part of the theory is the view that activity is a self-regulating system in which knowledge, behaviour and motivation correlate with one another. Another significant point is the approach to the concept of task. Each task is considered an activity determined by the characteristics of a particular situation and is aimed at achieving the task goal under the given conditions. From the SSAT perspective, task analysis involves the precise description of the activity structure during task performance. This structure is systematic and its description is given based on qualitative and quantitative methods. The task itself consists of logically organised cognitive and behavioural actions that are directed to achieve the goal of the task (Bedny, Meister, 1997). Thus, the whole hierarchical scheme of work activity can be seen as an activity aimed at the performance of a task through the conduction of cognitive and behavioural actions, and operations. In turn, a goal of a task organises the task elements into a holistic system. The realisation of the goal by the subject is a proviso for human work activity.

In terms of SSAT, human work activity is systematically organised. All the components of the motivational process that imparts energy to this activity are precisely distinguished. Both physical and mental actions are subject to observation and analysis. This allows the use of a wide variety of research methods - experimental, observation, psycho-physiological tests and more. The distinction between tasks, actions and activities, as well as between their outcomes, allows us to analyse the behaviour of all participants in the motivational process. This is also a good prerequisite for transdisciplinary research. For example, tasks and their structure can be analysed with management science tools. Actions and their outcomes can be explored with psychological instruments. Interactions between participants in the process can be studied with the help of sociology, interactions with the environment with the help of ergonomics, etc. In general, SSAT is one of the most relevant theories for interdisciplinary research, and it is one of its strengths. 
Activity theory is a powerful tool for theoretical research at a high level of abstraction, but it is not suitable for specific research with a practical focus. In contrast, SSAT has precisely designed units of analysis and capabilities for predicting the performance of human work systems.

Figure 1 shows the structure of the activity according to SSAT.

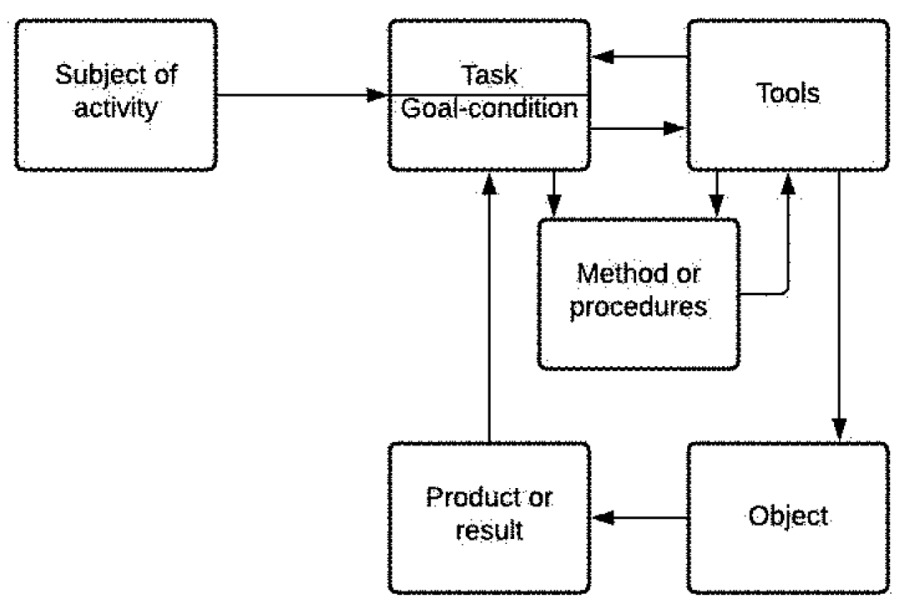

Figure 1. The structure of the activity

Source: (Bedny \& Karwowski, 2007, p.22)

According to Bedny \& Harris (2005), "Activity is a goal directed system, where cognition, behaviour and motivation are integrated and organised by a mechanism of self-regulation toward achieving a conscious goal" (Bedny \& Harris, 2005, p.130). One of the most popular presentations of activity theory today was developed by Engeström (Engeström, 1999). He proposes a scheme in the form of a triad, the main elements of which are the subject, the object and the outcome of the activity.

Unlike the scheme proposed by Engeström, the SSAT distinguishes between the concepts of goal and result. The goal is a cognitive mental representation of the desired future state of the object, while the result is the actual consequences of the activity. The result of activity may or may not match the goal. This implies that actions are constantly corrected. If the actual result of an activity does not coincide with the goal of the subject, then he or she must develop a new strategy to achieve the goal or completely reconsider their actions. This process of continuous adjustment of actions means that the feedback is permanently presented in the phenomena under consideration. The main steps of the process are shown in Figure 2.

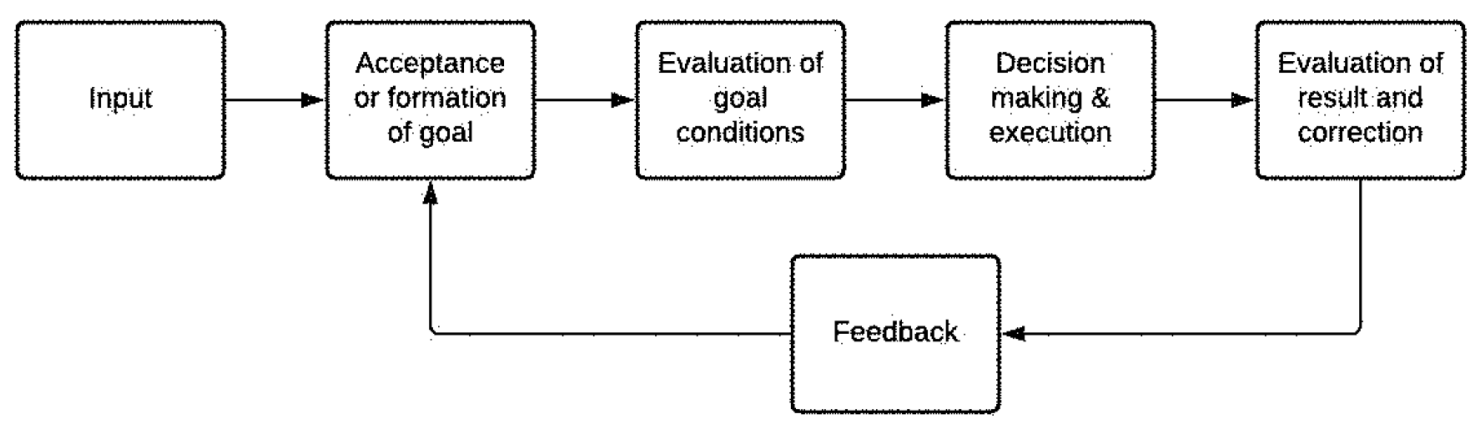

Figure 2. Goal and result according to SSAT

Source: (Bedny \& Harris, 2005, p.132) 
Another important concept for the theory is the motive. It is adopted by activity theory. A motive is present when the subject makes a semantic connection between his needs and the object of influence. Therefore, motivation is a complex phenomenon that contains both internal cognitive characteristics of the subject and situational variables. As the goals guide the activity, the motives give it the energy to arise. The motive may be characterized by varying intensity and the activity induced by it may be more or less desired by the subject. This will affect the efforts that the person is willing to make to achieve the goal. The classic view of the relationship between motive and a goal is that motive is an energy vector that gives the activity a goal-directed character (Leont'ev, 1981).

Figure 3 represents the structure of the activity from the point of view of practical research.

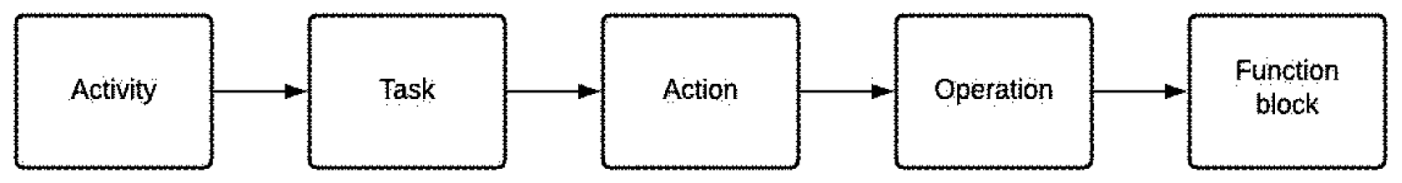

Figure 3. Research components of the activity

Source: (Bedny \& Harris, 2005, p.134)

The SSAT makes a clear distinction between objects of study and units of analysis. The reason is that opportunities are being sought to increase the practical applicability of research. In such an approach, the activity and the individual tasks that make it up are considered as an object of study. In turn, this object must be described with the help of various analytical units suitable for the purposes of the specific study.

As mentioned, the first two components of the scheme (activity and task) are considered as the object of study, and the rest - as specific units of analysis for a particular study. The main subject of the research is the defined human work activity. It consists of a set of certain tasks and manifests itself in the process of their implementation. The main analytical unit for the activity is the action. It can then be broken down into operations. Functional blocks can be considered as complete structures (macro blocks) or decomposed into smaller components (micro blocks) depending on the objectives of the study. Thus, it is possible to make a morphological analysis of the activity in depth.

In our particular case, we can use SSAT in two directions. The first is related to the definition of important work moments in the field of tourism business. For example, activities such as welcoming hotel guests, accommodation, dealing with complaints and requirements, etc. can be analysed. This will allow researchers to determine the topics from which to extract the necessary professional vocabulary. The second direction is related to the possibility to increase the motivation for learning of students. By its very nature, learning activity is a kind of work activity. This allows the teacher to decompose the learning activity into its morphological elements using SSAT. Then, using certain characteristics of the learners, to design the learning process in such a way as to increase their motivation and stimulate them to make more efforts to achieve the learning goals.

\section{MARKETING AND LEARNING ENGAGEMENT}

The idea of using marketing tools to increase the engagement of foreign language students may seem strange but only at first glance. We must take into account that modern marketing is not just business theory and practice but above all a philosophy and a way of thinking. Authors like Kotler believe that the idea of people and organisations achieving their goals through fair exchange with others is one of the achievements of the 20th century. In essence, seen as a phi- 
losophy, marketing is a means by which people (as individuals or organisations) achieve their goals through voluntary mutually beneficial exchanges with others (Kotler, 2000).

In the field of marketing, the concept of consumer engagement is relatively new. The first publications dedicated to this problem appeared after the beginning of the new century. Before that, from the middle of the last century until its end, the term consumer involvement was used. The reasons for this must be sought in two directions. The first one is related to the development of marketing theory and practice, and the second - to the development of modern information and communication technologies.

The researcher who introduced the concept of consumer involvement in marketing was Herbert Krugman (Krugman, 1965). Initially, he studied the impact of involvement on persuasive communications in marketing and the mass media. He pointed out that the phenomenon was too complex and its practical use required in-depth research. Later, Krugman proposed the first adequate instruments for measuring involvement (Krugman, 1967). With the increase of research in the field, the concept of felt involvement is confirmed. It is defined as a specific psychological experience of the motivated consumer (Celsi \& Olson, 1988). Further research found that felt involvement can manifest itself in two dimensions - as enduring or situational, as well as cognitive or affective (Richins, Bloch, \& McQuarrie, 1992).

It is gradually becoming clear that the most important dimension of involvement is its sustainability over time. From this point of view, involvement is enduring and situational. It is important to note that these two characteristics are not alternative. They can exist together and separately to some extent. The relationship between them needs to be discussed more closely below. At this stage, we will note that in the cases of enduring involvement the observed individual demonstrates a strong interest in an object (product, brand) or activity over a long period. Such behaviour occurs when there is a strong connection between the object and the significant needs of the individual. This phenomenon is relatively rare. Situational involvement is much more common. In these cases, the characteristics of involvement are determined by the specific parameters of the observed situation. For instance, many people do not have a specific attitude towards household appliances, but experience a very high level of involvement when an appliance breaks down and needs to be replaced with a new one. Exploring the relationship between enduring and situational involvement is not an easy task. This relationship is particularly important because the overall level of involvement depends on the levels of enduring and situational involvement experienced by the subject. This means that enduring and situational involvement must be examined separately, as well as the mechanisms by which these two dimensions interact. Enduring involvement is a consequence of the unique value orientations and stable attitudes of the individual. Because psychology has a wide range of tools for exploring values, attitudes, and preferences, enduring involvement can be relatively accurately explored and measured. In terms of situational involvement, however, things are quite different. In practice, it cannot be separated from long-term involvement and explored on its own. The observed individual always experiences some level of enduring involvement (high or low depending on his individual attitudes and values) and at the same time some level of situational involvement (depending on the parameters of the specific situation). In other words, we can observe and explore enduring involvement relatively independently. In certain cases, we can observe and explore enduring and situational involvement together. But, it is not possible to observe and study only situational involvement, because enduring involvement is constantly manifested over time. This means that in order to get an idea of situational involvement, we need to shift the focus of research from people to the situations in which they act. Observing certain situations makes it pos- 
sible to describe the behavioural response of large groups of people. If these behavioural responses are systematized, it is possible to identify sustainable trends and causal relationships between the characteristics of situations and the behaviour of individuals (Houston \& Rothschild, 1978).

Research into the way in which enduring and situational involvement interact to build the resulting level of involvement yields very interesting results. It turns out that the use of complex models of interaction does not contribute much to increasing the explanatory and predictive value of research. Simple additive models prove to be sufficiently precise and effective (Richins, Bloch, \& McQuarrie, 1992). The most interesting finding from the research on the interaction between enduring and situational involvement is that the input levels of initial enduring involvement do not significantly affect the perceived situational involvement. In other words, high initial levels of enduring involvement before the individual is in a particular situation do not make situational involvement more intense. Accordingly, in the opposite case, at low initial levels of enduring involvement, when in a certain situation, the evoked situational involvement is not suppressed. The conclusion is that the result of the joint action of enduring and situational involvement depends mainly on the perceived level of situational involvement. The complex response of the subject is always proportional to the level of situational involvement but has a different intensity depending on the initial levels of enduring involvement. This finding is very important both for the development of marketing theory nowadays and for the purposes of increasing the motivation of students in learning a foreign language. Both marketers and educators need to focus on finding ways to increase situational involvement.

The widespread use of information and communication technologies in the relations between business organisations and their customers nowadays drastically changes modern marketing. The ability of marketers to implement multi-channel strategies increases the client's strength in his relationships with business organisations, while intensifying competition between these organisations. Nowadays, customers can make serious purchases with just one click of a computer mouse while having fun or doing some other work. The theoretical concepts of classical marketing, including those related to consumer involvement, are no longer sufficient to gain significant competitive advantages. This is the reason why marketers have shifted from the concept of involvement to the concept of engagement. It is obvious that there is a connection between these concepts. In essence, in modern marketing the complex behavioural response that results from enduring involvement and behavioural attitudes in a particular situation that is caused by situational involvement is called engagement. However, this connection needs to be clarified more precisely.

There is a difference between involvement and engagement. In the case of involvement, the emphasis is on the internal psychological characteristics, and the case of engagement on the predisposition to action (Vivek, Beatty \& Morgan, 2012). This difference is not sharp. Both involvement and engagement are concepts borrowed from psychology. As a theoretical construct, involvement is focused on internal characteristics per se, and engagement on internal characteristics that elicit a particular behavioural response. For this reason, we state that complex involvement which includes the subject's behavioural responses to a particular situation can to some degree be seen as engagement. Naturally, the meaning of this statement is not to confuse the concepts, but to outline the historical continuity and the connection between them.

Although relatively new, the concept of consumer engagement is already used in marketing and this gives positive results. In order to show a certain level of engagement, the subjects surveyed must first reach a certain level of involvement. In order to monitor this process, it is necessary 
to use adequate tools to measure involvement and engagement. There are tools for measuring involvement that have been developed by traditional marketing and have proven their adequacy over a long period (Bloch, 1981). Tools for research and measurement of consumer engagement are being developed by modern marketing (Vivek, Beatty, Dalela, \& Morgan, 2014). Research shows that engagement tends to be viewed and measured as an attitude. This presupposes to analyse and measure adequately three main components: cognitive, affective and behavioural (volitional). Modern psychology has precise tools for measuring attitudes and they have to be adapted to the needs of marketing and language learning. In this regard, language teachers can use the experience already gained in the field of marketing. Due to the interest of business in developing new approaches that can be used to gain a competitive advantage, there is already extensive experience from research and this experience is constantly enriched. In modern conditions, marketing and sales are becoming increasingly associated with the use of information and communication technologies. This allows marketers to monitor the behavioural reactions of their customers in real time. In addition, modern technologies allow collecting data for a given group of users simultaneously from different sources - social networks, voluntary activities, political and social events, shopping behaviour, preferred financial services, etc.

As mentioned, in order to increase the overall final involvement, it is necessary to focus on situational involvement. For this purpose, a separate group of marketing communications has been developed - sales promotion. In essence, sales promotion is any action of the organisation designed to increase sales, provide an additional incentive to buy or encourage the use or testing of a product or service. Sales promotion comes in many forms, but they all focus on convincing the target audience to become a customer. A wide variety of sales promotion tools have been developed for marketing purposes. In the new high-tech conditions, this set of tools is constantly enriched.

Although difficult to influence, enduring involvement is also important. Its level can be increased through persuasive communications that improve consumer awareness of the product. The idea is to build beliefs that a product can play a more significant role in the life of the consumer. The level of enduring involvement can be increased through persuasive communications that improve consumer awareness of the product. For this purpose, informative advertising and communications in the field of public relations are used. Although this task is more difficult, marketers do not stop their efforts in this direction.

In conclusion, language teachers can use marketing tools to increase the involvement and engagement of their students. To this end, marketing tools must be adapted to the requirements of training. Each marketing tool has its analogue. For example, informative advertising corresponds to traditional lectures, sales promotion corresponds to the provision of additional incentives and diversification of the learning environment and learning tasks to increase the interest of students, etc. Following the logic of marketing models, educators have to select the most appropriate tools to influence learners. Their efforts need to focus on both enduring and situational involvement, with a focus on the latter.

\section{AN INTERDISCIPLINARY APPROACH TO ENGLISH FOR TOURISM}

Along with textbooks, course packs and conventional materials, we introduced several novelties based on the new learner characteristics and contexts and provoking greater curiosity. Curiosity is expected to lead to greater interest and engagement similarly to the involvement in the process of purchasing. Along with this, although academic courses have a strict syllabus to follow, 
we use SSAT to determine which topics and related vocabulary to pay greater attention to in the learning process in order to optimise course effectiveness concerning the particular student groups. Using textbooks, course packs and conventional learning materials, involving the traditional activities of reading, listening, speaking and writing may not provoke the expected engagement of modern students. However, introducing tasks challenging creativity, team work and peer comparison, and including social media can be beneficial to student performance.

In this regard, our first suggestion is related to the introduction of more interactive tasks created by the ESP practitioner and involving the work with the immense electronic databases and the use of social media. An example of such tasks is tasks related to the analysis of specific problems and trends in tourism. Students are required to do their own research and find reliable information on the consequences of the pandemic for the sector of tourism in general, for a particular country or tourist service. Then they have to process and analyse the information gathered by focusing on the most important implications or trends, make recommendations and, finally, prepare a presentation for their colleagues. After the presentation, they are expected to share with the group their personal view on the issue. The other students, in turn, are required to provide feedback on their colleague's performance by analysing the strengths and weaknesses of the task accomplishment. A task like this involves student resourcefulness and critical thinking and fosters the acquisition of subject matter together with specialised knowledge and skills related to the professional communication in the area such as presentations, summarising, analysis of trends and graphs, processing of specialised information; consulting and collaborating with peers similarly to team work at work, assessing peer performance. The specific listening, writing, reading and speaking skills are developed and improved in a more competitive and stimulating environment leading to higher engagement and enhanced performance. Another beneficial effect is the skill to find reliable sources of data and to process information which is crucial for the success of an expert in economics and especially in tourism where there are a lot of trends, options and opportunities to be anticipated, predicted, analysed and taken advantage in terms of survival and competitiveness. In terms of marketing, we increase consumer involvement and attract attention by using a combination of informative media advertising and offering small gifts at the point of purchase. In learning, the traditional lectures play the role of informative advertising and since students perceive the Internet as a place primarily for entertainment, the tasks including it and the social media are, in turn, perceived as gifts. This technique contributes to the diversification of "boring" lectures and the facilitated understanding of learning material. Thus product knowledge is increased and, correspondingly, enduring involvement. In addition, gifts stimulate a positive attitude which is how situational involvement is enhanced. As a result, there is higher consumer engagement.

Interactive projects are our second suggestion. Project-based learning (PBL) has become popular and widely used over the last years for the advantages it brings to a course in terms of student motivation, self-direction and autonomy. However, the novelties we introduced with our project add value by increasing cognitive and behavioural engagement. They are new and innovative in terms of project structure, objectives and content and intended to offer a balanced acquisition and mastering of the skills for fluent business communication in situations simulating the professional context of tourism. Towards the end of their course in English for tourism, our students are assigned three projects - two individual ones and one group project. The first individual one is about a destination in Bulgaria because it is the mother country of the majority of our students. Learners are required to conduct research by gathering reliable information about the place of interest in terms of geography, landmarks, means of transportation, types of accommodation and tourism, what to do and visit. The second one is focused on a foreign country. Students are 
expected to prepare a brief about a country once again by doing their own research, collecting and processing reliable information about the key features of the destination, including geography, climate, health requirements and warnings, landmarks and sights, places of interest, currency, economic and social specifics relevant to foreign visitors, accommodation, etc. In addition, each student has to make a presentation to familiarise their group with the results from their research as well as to try to convince them as if they were real customers why the destination is worth visiting. In turn, the students from the group are supposed to provide feedback about the strengths and weaknesses of their colleague's presentation similarly to what a lecturer does when reviewing the second project brief and the first project paper. Thus students can acquire and improve the specific linguistic knowledge and skills - the specific communicative competence, in terms of terminology, grammatical structures, register, context, discourse, etc. Furthermore, by participating in such projects which simulate the real-life routine of an employee in tourism, they can gain practical experience from different perspectives and be prepared for successful realisation in the sector of tourism. They can enhance the soft skills for synthesising, analysing and summarising as well. Similar to promotions and samples in marketing, intended to increase consumer interest and involvement, our projects provide a personal experience aimed at revealing the advantages of a product that customers may not have been aware of.

The group project is focused on communication with customers and customer satisfaction. Students have to prepare questionnaires related to the service offered by an agent in tourism such as a hotel, a restaurant, a travel agency, a tour operator, a carrier and do a customer survey. Having collected these data, they need to analyse them and write a report about their findings. And, finally, they are expected to prepare a presentation about the survey with an introductory information about the business surveyed. Through this interactive project involving several activities and including all linguistic skills for specific purposes we achieve the following goals: increased student communicative competence in writing formal documents, in doing scientific work in English and for the purposes of tourism, enhanced skills for effective presentations, both written and oral, in tourism. Student inventiveness is encouraged and revealed in the preparation and design of the questionnaires and presentations, the selection of pictures, the choice of a business and the preparation of this business's brief. After the presentations, there is always a discussion about student performance and impressions allowing for another perspective - that of the analyst, consultant and peer reviewer. This way peer competition encouraged soft skills developed such as team work or performance assessment which helps students become better prepared for work in a competitive environment like the sector of tourism.

The last suggestion is related to visits. The visits students are offered in our courses are of two kinds with English as the language of communication. The first kind of visits are those of distinguished professionals in the sector of tourism who give a lecture and then discuss with the students a burning issue or an essential aspect of their work and familiarise the audience with the institution they represent - its structure, culture, achievements and strategies for success. They also talk about the opportunities their organisation provides for internships, work and business events. These academic visits can also include university alumni or 3- and 4-year students who have already started their careers or have already succeeded by winning a prize, starting their own business in the sector or offering a novel tourist product or service. This way, by sharing their own experience with younger students, they inspire and provide peer feedback. Through these visits students view their future career from a different angle and can find additional motives for development and learning engagement. The second kind of visits are the practical visits to businesses in tourism. Thus, students can gain practical experience, see how the company 
functions from the inside and get personal insights into business activity. For instance, last year our students visited a family hotel, a big hotel in the capital and a guest house. Then, they had visits to an amusement park and a catering company. By familiarising with the way these businesses are organised and operate and by meeting the managerial staff, students were provided a first-hand experience which they found much more involving than their lectures and seminars. Therefore, combining classical academic education with more unconventional forms of learning, we provoked greater interest and managed to convince learners why some disciplines or topics that they usually find difficult or useless are in fact an integral part of their courses and a must for a future expert in tourism. Needless to say, motivation was enhanced, ESP acquisition improved significantly and overall learning results, including knowledge of subject matter and professional skills, were much higher compared to the traditional academic approach. The high-ranking professionals involved in learning play the role for students that celebrities from advertisements play to consumers - endorse a product and convince users in its quality, thus leading to a higher level of engagement.

\section{CONCLUSION}

Applying an interdisciplinary approach involving psychology, marketing and methodology of foreign language teaching, we managed to optimise an academic course in English for tourism by making a parallel between learners and consumers. Students are seen as the consumers opting for the educational product a higher institution offers, and their engagement is encouraged and increased similarly to consumer involvement in marketing by using marketing techniques in accordance with the novel interactive tasks, projects or visits that we introduced. Thus, through the combination of modern teaching and marketing and based on psychology, we manage to use adequate tools that ultimately lead to increased student engagement and hence to more effective ESP acquisition in the sector of tourism. Student performance is facilitated and improved significantly owing to the more balanced and motivating way of teaching the specific linguistic content in a more relaxed environment along with the provision of a more learner-centred education in subject matter of tourism.

This approach was piloted with students last year and the feedback received was very positive and encouraging. In order to examine its effectiveness empirically, we are in a process of collecting quantitative and qualitative data. The processing of the data gathered will provide a basis for a more elaborate analysis and optimisation of the proposed approach. Since the suggested interdisciplinary approach was developed for the sector of tourism but is intrinsically related to education, it could successfully be applied to other disciplines and we believe that the synergy it ensures can add value to the quality of the overall educational product, namely a bachelor or master programme and hence to the welfare of the business and society.

\section{REFERENCES}

Ashwin P., \& McVitty D. (2015). The Meanings of Student Engagement: Implications for Policies and Practices. In: A. Curaj, L. Matei, R. Pricopie, J. Salmi, \& P. Scott (Eds), The European Higher Education Area (pp. 343-359). Springer, Cham. https://doi.org/10.1007/9783-319-20877-0_23.

https://link.springer.com/content/pdf/10.1007/978-3-319-20877-0_23.pdf

Bedny, G., \& Karwowski, W. (2007). A systemic-structural theory of activity. Routledge: CRC Press. 
Bedny, G., \& Harris, S. (2005) The Systemic-Structural Theory of Activity: Applications to the Study of Human Work. Mind, Culture, and Activity, 12 (2), 128-147. https://doi.org/10.1207/ s15327884mca1202_4

Bedny, G. Z., (2004), Preface, Theoretical Issues in Ergonomics Science (Special Issue), 5 (4), $249-254$.

Bedny, G., \& Karwowski, W., (2013), Analysis of strategies employed during upper extremity positioning actions, Theoretical Issues in Ergonomics Science, 14 (2), 175-194.

Bedny, G., \& Meister, D., (1997), The Russian Theory of Activity: Current Application to Design and Learning, Mahwah, Lawrence Erlbaum Associates, New Jersey.

Bedny, G., Bedny, I. \& Karwowski, W., (2019), Applied and Systemic-Structural Activity Theories, In G. Bedny, I. Bedny, (Ed.), Applied and Systemic-Structural Activity Theory: Advances in Studies of Human Performance, Taylor \& Francis Group, NY, 3 - 25.

Bender, W. (2017). 20 Strategies for increasing student engagement. Learning Sciences International.

Bloch, P. (1981). An Exploration Into the Scaling of Consumers' Involvement With a Product Class. NA - Advances in Consumer Research, 08, 61-65. https://www.acrwebsite.org/volumes/9786/volumes/v08/NA-08

Carter, D. (1983). Some propositions about ESP. The ESP Journal, 2, 131-137.

Celsi, R. L., \& Olson, J. C. (1988). The Role of Involvement in Attention and Comprehension Processes. Journal of Consumer Research, 15(2), 210-224. https://doi.org/10.1086/209158

Cummins, J. (1979). Cognitive/academic language proficiency, linguistic interdependence, the optimum age question and some other matters. Working Papers on Bilingualism, 19, 121129.a

De Bot, K.D., Lowie, W. \& Verspoor, M. (2005). Second Language Acquisition: An Advanced Resource book. New York: Routledge.

Dudley-Evans, T., \& St John, M. (1998). Developments in ESP: A multi-disciplinary approach. Cambridge: Cambridge University Press. https://doi.org/10.1016/S0889-4906(99)00026-5

Engeström, Y. (1999). Activity theory and individual and social transformation. In Y. Engeström \& R. Miettinen \& R.-L. Punamäki (Eds.), Perspectives on Activity Theory (pp. 1938). Cambridge: Cambridge University Press.

Engeström, Y., (2015), Learning By Expanding: An Activity Theoretical Approach To Developmental Research, Cambridge University Press, Helsinki.

Fredricks, J. A., Blumenfeld, P. \& Paris, A. (2004) School Engagement: Potential of the Concept, State of the Evidence. Review of Educational Research 74, no. 1. http://www.isbe.net/ learningsupports/pdfs/engagement-concept.pdf.

Houston, M. J., \& Rothschild, M. L. (1978). Conceptual and Methodological Perspectives on Involvement. In S. Jain (Ed.), Research Frontiers in Marketing: Dialogues and Directions (pp. 184-187). Chicago: American Marketing Association.

Kotler, P. (2000) Marketing Management, Millennium Edition (10th ed.). New Jersey: Prentice-Hall, Inc.

Krugman, H. (1965). The Impact of Television Advertising: Learning Without Involvement. Public Opinion Quarterly, 29(3), 349-356.

Krugman, H. (1967) The Measurement of Advertising Involvement. Public Opinion Quarterly, 30(4), 583-596.

Leont'ev, A. N. (1981). Problems of the Development of the Mind. Moscow: Progress.

Martin, J. \& Torres, A. (2016). User's guide and toolkit for the surveys of student engagement: The High school survey of student engagement (HSSSE) and the Middle grades survey of student engagement (MGSSE). National Association of Independent Schools, USA. 
Richins, M. L., Bloch, P. H., \& McQuarrie, E. F. (1992) How Enduring and Situational Involvement Combine to Create Involvement Responses. Journal of Consumer Psychology, September, 143-154. https://doi.org/10.1016/S1057-7408(08)80054-X

Vivek, S. D., Beatty, S. E., Dalela, V., \& Morgan, R. M. (2014). A Generalized Multidimensional Scale for Measuring Customer Engagement. Journal of Marketing Theory \& Practice, 22 (4), 401-420. https://doi.org/10.2753/MTP1069-6679220404

Vivek, S. D., Beatty, S.E., \& Morgan, R.M. (2012), Customer Engagement: Exploring Customer Relationships Beyond Purchase. Journal of Marketing Theory and Practice, 20 (2), 127-149. https://doi.org/10.2753/MTP1069-6679200201

Windham, C. (2005). The Student's Perspective. In D. Oblinger \& J. Oblinger (Eds), Educating the Net generation (pp. 5.1-5.16). Boulder, CO: EDUCAUSE. http://www.educause.edu/ educatingthenetgen

Yasnitsky, A., (2018), Vygotsky: An Intellectual Biography, Routledge Abingdon, NY. 
